\title{
Empathy as a Tool for Embodiment Processes in Vocal Performance
}

\author{
ERIN HEISEL
}

\begin{abstract}
One way of understanding empathy in music performance is as a process by which singers closely identify with the characters they encounter and portray in opera or art song. As singers embody these characters, they literally give them voice. Music performance humanizes characters as well as performers and audiences through shared empathetic engagement, resulting in the development of knowledge and understanding within and beyond the immediate musical experience. What is the process a singer goes through in empathizing with a character? How can young classical or musical theatre singers learn to empathize with the characters they are tasked with portraying, even when they may find the characters or their behavior to fall outside of their own moral convictions? This paper posits that empathy is a necessary part of the role preparation process for singers and introduces the "role journal" as a way for young singers to track embodiment processes and develop healthy habits of empathy and boundaries in their work.
\end{abstract}

Submitted 2014 March 28; accepted 2015 April 8.

KEYWORDS: empathy, vocal performance, singing, vocal pedagogy, opera, music

AS empathy becomes a more popular subset of the fields of music psychology and music performance philosophy, it is important to remember that live music is an immediate, visceral experience for performers and audiences. The music performance experience functions as a multi-faceted vortex of communication passing not only between performers, between audience members, and between collective and individual subsets of performers and audience members, but also between the characters realized through the performance, whether embodied by the performers or not (orchestral tone poems, for example, may create a character without actual embodiment), and finally creating links across time as performers and audience members engage, in a sense, with a composer. Within the multiplicity of communication processes in performance situations, perhaps the most significant are the most intimate. I suggest that the most intimate experience of empathy in music is between a singer and the character he or she portrays. The singer who embodies and realizes a character engages in a process of intimate and meaningful empathy with the character throughout preparation and performance processes. By extension, audience members may feel an empathic connection to characters they see on the stage, both through the performer's portrayal as well as through the music experience. For these reasons, I contend that conceptual theories of empathy in music can benefit from including practical applications for artists. Mindful recognition and development of empathy in music, especially in vocal performance, can enhance the experiences of performers and their audiences.

According to music education philosopher David Elliott, "the concept of music as knowledge is rich with possibilities" (Elliot, 1991, p. 21). As an extension of this notion, I posit that the creation and development of knowledge in and through music is related to empathy in music performance experiences. In this article, I will consider empathy in the role preparation process for singers as a means by which a singer can facilitate his or her own growth, including both new knowledge of a character as well as knowledge of preparation and performance processes. I also suggest that young singers can and should be encouraged to document experiences in empathic embodiment through role preparation to preserve the experience, facilitate discussion, and to fuel and inspire future performances. Documentation also serves the development of personal, emotional, and interpretative knowledge and skills student singers can use beyond the educational setting.

Interestingly, in his article "Empathy: Implications for Theatre Research," George Gunkle argues: 
To continue to refer to the interaction between spectator and actor in the theatre experience as "empathy" is to mask the multiplicity of processes, each of which may have a separate claim upon our attention. Such carelessness blends perhaps vital distinctions into an undifferentiated vagueness while, at the same time, providing us with a label that conceals a very real ignorance. To invoke the word, empathy, in discussing interpersonal processes in the theatre today can only continue to stall inquiry rather than stimulate it into a more exacting search. (Gunkle, 1963, p.23)

Total abandonment of the term "empathy" in theatre arts (including opera) seems to me to be dangerously close to "throwing the baby out with the bathwater." Although there is certainly a danger in the overuse of the word that could lead to oversimplification of the term or the theatre event and an eventual loss of meaning for both, I think another solution is to reconsider the placement of empathy in aesthetic research. If, as I will propose, empathy is an essential part of a complicated and humanizing process through which knowledge is created and communicated, then, it seems to me, empathy is also the means by which inquiry into artistic methods of communicating and understanding emotions is made possible. In other words, empathy is an entryway into the profound humanizing that occurs through the embodiment of characters on a stage. This is a process through which singers and audience members create and communicate deeper and broader understandings of the human condition. Rather than eliminate empathy from artistic research, perhaps we should start with it, not only in discussions regarding empathy in music performance, but also in developing pedagogies for young musicians, especially singers.

Considering empathy in vocal performance is not without challenges, the first of which is to begin to define what empathy means in this context. This paper will briefly explore a means by which empathy can be understood in relation to the work of classical singers and the need for developing empathy in young singers. The paper will finally propose a method by which young singers can learn to examine their own artistic development, as well as the characters they portray, with empathy.

\section{DEFINING EMPATHY FOR VOCAL PERFORMANCE}

Empathy in vocal music performance can in part be considered as a means by which singers closely identify with the characters they encounter and portray in opera and art song.[1] In role preparation, singers begin to intimately know a (sometimes) unreal person and learn to see the story or situation through the character's eyes. In his article, "Empathy, Emotion, and Ekstasis in the Patient: Physician Relationship," Neil Francis Pembroke writes, "The original meaning of empathy, then, is the act of feeling oneself into the experience of another person in order to understand it as fully as possible" (Pembroke, 2007, p. 290).[2] Singers enter the lives of the characters they portray, acting and reacting through that character's view and experience. This becomes a living experience for the singer and for the audience as well. Empathy in the work of singers is an important part of a humanizing process of embodiment whereby the singer gives the character voice.

I posit that empathic experiences in music can be transformative, particularly in the field of vocal performance. According to Herbert Blau (1990, p. 270), "Performance may transform the one performing. That it has the capacity to transform seems to be universal." Moments of deep empathy with a character can be transformative for singers even beyond the immediate performance experience. Singers may find themselves aware of new depths of human emotion or understanding as they consider a character's plight and may even find their perceptions of the present world changed through these experiences. Within the moment of the performance, as performance theorist Richard Schechner writes, "the doing of the action of a feeling is enough to arouse the feeling both in the doer and in the receiver" (Schechner, 1990, p. 41). Singers who allow natural physical responses to emotions experienced by a character, in the forms of gestures, for example, may find that the doing of these actions leads to deeper empathic engagement with the character. The transition from the feeling of an emotion to the doing of the emotion, Schechner's "the action of the feeling," is a step towards what I call empathic embodiment. For this reason, I believe that a useful definition of empathy for vocal performance should also consider the notions of physical action and embodiment.

I also suggest that a definition of empathy for the purposes of practical application should include the importance of personal boundaries. An extension of the work of Blau and Schechner is that singers in the process of empathic embodiment may themselves experience the emotions of the characters they portray. These emotions may be extreme and in this case, the full experience of these emotions would 
understandably get in the way of the singing. For example, if a singer portraying Pamina in Mozart's The Magic Flute truly experiences the profound despair, loss, and confusion the character does in the suicide contemplation scene, she could not possibly sing it. In "Emotions in Music," Jenefer Robinson and Robert Hatten state, "As for performers, it is very difficult if not impossible for them to perform in a way that is expressive of inconsolable sadness while simultaneously expressing that degree of sadness themselves" (Hatten \& Robinson, 2012, p. 75). In moments like this, singers need to strike a balance between empathy and the necessary personal distance from the character or situation. Perhaps one useful way of thinking of this is that the character experiences the emotion while the singer portrays the character's emotion through embodiment. Such thinking might allow a singer to, in these moments, enable the one-ness of embodiment while, simultaneously, sustain an important boundary between the inner world of the character and performance work of the singer. This dual perspective may allow not only a deeper understanding of the character but also provide a useful way for the singer to monitor his or her own process and development. I further suggest that this can serve as a platform for the singer to enable his or her own emotional and artistic growth while achieving new levels of vocal, musical, and/or interpretative skill. In any case, a definition of empathy for vocal performance must address the important issue of boundaries in performance for the singer.

Finally, I posit that a definition of empathy in vocal performance should include audience experience. Audience members may engage fully in music through active listening, witnessing great virtuosity, or deeply empathizing with characters portrayed, or perhaps also with the singers tasked with the portrayal. In any case, audience members may experience or develop new ideas of human understanding or achievement during music performance and in doing so, humanize performers, characters, and perhaps even themselves as the artistic experience challenges previously held ideas of human ability. For example, an audience member watching Lucia's mad scene may become fully enraptured not only by Lucia's depth of emotion, but also by the singer's extreme virtuosic and interpretive ability. Lucia becomes fully humanized through the audience member's engagement with the performance, which includes not only the singer's empathic embodiment of the character, but also the audience member's acceptance of and empathy with Lucia's reality on the stage. Furthermore, the audience member, while watching a performer who is able to portray this character realistically while also executing the extreme vocal demands of the role with ease, may also reconsider the limits of human potential, much like watching a record-breaking achievement in an Olympic sport. In moments like these, where empathy for a character in an extreme situation and incredible virtuosic skill in presentation of the character come together, I suggest that the potential for the audience to develop or create new knowledge or understanding may be greatest, whether that knowledge is outer (knowledge of the piece or the world) or inner (knowledge of the self as considered in response to experience artistic achievement). An audience member may, for example, come to a deeper understanding of him- or herself, of others (including the singer or the character portrayed), of the piece, or to perhaps challenge broader notions of socio-political situations portrayed by the piece, the time period of composition or the time portrayed (which may not be the same), or, through metaphor or direct representation, of the present world. For this reason, it is my contention that a definition of empathy for vocal performance should also include implications of empathy in performance for the audience.

\section{THE IMPORTANCE OF DEVELOPING EMPATHY IN YOUNG SINGERS}

I am reminded of a masterclass I attended several years ago; a young soprano was performing "Obéissons quand leur voix appelle," the Gavotte from Massenet's Manon. Though she sang it well, her performance was utterly unconvincing. The teacher asked for a description of the character Manon, her life experience, and the circumstances in the plot at the moment she sings the aria. Without hesitation and with force, the young singer replied, "She's a whore." She repeated this statement several times throughout her explanation of the story, clearly advertising her disdain for the character she was tasked with portraying. Her performance indeed suffered; it is possible that her inability to empathize with the character had led her to choose what, to her, probably seemed like the most sympathetic rendering of the aria she could muster, which unfortunately was simply to stand on the stage, devoid of motion or emotion, and perform the piece as though she was reading from a phone book.

Her interpretation of the character notwithstanding, there is something important to learn from this. Is it not possible to accept and portray characters who, to understate the drama of opera, are "bad," not likeable, or, more generally, do not behave in a manner consistent with a performer's moral sense? We know of course that it is; plenty of astoundingly good Scarpias, for example, tread upon opera stages and 
leave indelible marks on the memories of audience members. What of the relationship between this kind of character and the singer tasked with the portrayal? How can young singers learn to manage conflicting feelings when challenged by characters whose behavior they find reprehensible? There are certainly plenty of examples in opera of behavior that one might hope a singer would not be interested in committing in "real life," making this a relevant and important point in terms of empathic work in vocal performance.

\section{IMAGINATION AND IMPLICATIONS FOR VOCAL PEDAGOGY}

I posit that singers should be in the habit of developing empathy for the characters they embody; in this way, they can begin the process of humanizing the characters in an honest way. One way into this is through the imagination. In this section, I will first consider the role of imagination in developing empathy in role portrayal and then I will revisit two previously mentioned facets of empathy, boundaries and judgment, offering suggestions on how these can be effectively addressed in pedagogical situations for young singers.

Daniel Putnam argues, "the role of imagination is critical in all forms of empathy" (Putnam, 1994, p. 100). If the singer cannot or will not clearly imagine the emotions and motivations of a character, accepting and understanding this person as human (and therefore flawed), I suggest they cannot begin an empathic embodiment process that will yield honest portrayal. Singers might consider the following questions as they imagine the character and begin to create a relationship to them: How are the characters like them? What emotions does the character experience that the singer can understand, even if the emotions are reactions to experiences or situations outside a singer's life experience (as they most likely are)? According to shame and vulnerability researcher Brené Brown, "Empathy is connecting with the emotion that someone is experiencing, not the event or circumstance" (Brown, 2012, p. 81). A first step is to imagine the character's emotional responses to the surrounding situation, even if the singer has never personally experienced anything similar. A singer can imagine jealousy, rage, or fear without having committed murder (for example, in Tosca), or sorrow at the prospect of betrayal, like the Countess in Le Nozze di Figaro, without having experienced it firsthand. A character must first be seen as human by the singer in order to be considered so by an audience; looking for common ground in emotional experiences is a useful step in this process.

Furthermore, as Putnam writes, "if empathy is not strong enough and imaginative emotions are too faint, then no simulation occurs, and we have not engaged the work of art" (Putnam, 1994, p. 100). For example, the aforementioned soprano could learn to feel Manon's joy in Act III despite perhaps wishing the character had chosen differently in the previous act. In any case, if the singer is not fully engaged in the work, he or she loses an opportunity for understanding and growth and, as in the case of the young singer and her Manon, the performance may suffer as well. Relatedly, many voice teachers have watched young singers who thought they were being overly expressive instead perform with blank and disinterested looks on their faces. Most young singers can go much further in their portrayals than they think and developing empathy by exploiting the imagination to make situations feel more real, vivid, and relevant to the singer is one way to encourage experimentation and growth in this area.

Being fully engaged in a piece, however, can be a risky thing for a singer. Healthy and necessary boundaries, as previously discussed, allow a singer to portray deeply sad moments in opera, like Pamina's suicide contemplation scene, without losing a sense of self or the ability to sing in the moment. A useful exercise in a safe rehearsal or practice setting is to allow the character's emotions to take over, such that singers can learn what it feels like when this happens and how to bring themselves back if things start to go too far. Young singers can learn how to recognize when they can go further and how far they can go before things like tone quality or identity (theirs or the character's) might be compromised. Singers can learn where the boundary needs to be and should be empowered to experiment with this as they become comfortable.

Boundaries can also be useful if the singer finds the character or the character's behavior to be personally offensive. In this situation, where empathy is more difficult to cultivate, the boundary can help reinforce the idea that the character's identity is not to be confused with the singer's. In my work as a pedagogue, I have noticed that judgment is the defense mechanism young singers may turn to when confronted with characters they don't like or situations they don't approve of. In life and in art, I find it is always difficult to empathize with people we don't like, such as may have been the case with the young singer attempting to portray Manon. It takes a level of maturity in a young singer to effectively do this, to be sure. I contend that it is nevertheless important that young singers learn to view characters with empathy 
and without judgment. Good understanding of personal boundaries can help young singers negotiate this and give them an entryway into imagination processes they can use to begin to develop empathy in their work, thus enabling personal and interpretive growth.

The following section proposes a reflective writing exercise for young singers for use in the process of studying new opera roles. This exercise allows the student singer the opportunity to create a case study of the role preparation experience through documentation of empathic and boundary development, as well as of personal growth in preparation and performance processes.

\section{ENHANCING EMPATHY IN MUSIC PREPARATION PROCESSES}

Many professional singers are able to navigate different forms of preparation simultaneously throughout rehearsal and performance processes, for example, musical rehearsals, staging rehearsals, general practice, specialized diction coaching, etc., all while considering the empathic development of the character they portray. How can students effectively learn this skill? How can they develop healthy habits and study practices that support and enhance empathy in role preparation? How can a young singer learn to view the characters he or she portrays with an empathic understanding of the character's unique situation? Further, how can a young singer learn to create and nurture boundaries that simultaneously support and develop both his or her own artistic identity as well as the identity of the character, as realized through this embodiment process?

I propose a method of journaling, guided and unguided, that would allow students the time and means to consider themselves as both separate from and crucial to the realization of the characters they study, while the character's development is crucial to their own personal growth. Keeping a "role journal" the first time a young singer encounters a new role would give the singer a way to assess his or her empathic reactions to characters as well as track personal growth through preparation and performance processes. This documentation can offer student singers insights into themselves and their work habits, offer a place where they can record changes and new ideas about the role that emerge through the rehearsal process, and, most importantly, allow them to record observations about their growth as interpreters. A practice of writing and reflection during the empathic process of embodiment would train young singers to consider character development and personal development as both separate and connected. The separation is important as it develops necessary boundaries for performance processes, and the connection is important as its existence allows for an empathic humanizing of the character through the singer that the audience can experience as real, present, and honest. Finally, in a culture of perfectionism, students can learn to view themselves and their work with empathy.

A worksheet or set of guided questions for a student singer to consider as he or she prepares a new score should certainly include basic biographical information about the character as way to monitor that the student does the basic "homework" of role preparation. Beyond this, the singer should consider how the character interacts with and reacts to surrounding people and events. What emotions does the character experience and what behaviors do they exhibit in these situations? How does the music communicate this? What sorts of things does the music tell us about a character that the text and story do not? Students should begin to consider this information as soon as they pick up a new score and should be in the habit of reconsidering it as their understanding of the character grows.

Students can also use these "role journals" to consider issues of physical embodiment through empathy in role preparation. How does it feel to share their bodies with these unreal people, in these circumstances (both entering the world of the opera and in rehearsal situations)? How does it feel to move like they move and how is the singer transformed through this work? Where is it easy to empathize with the character and where is the character in conflict with the student's personal, moral, or spiritual convictions? How does the singer meet these challenges and come to empathize with the character? What boundaries must the singer cultivate to be successful in this situation, and how does it feel to go beyond these boundaries in a practice session or safe rehearsal space? Students can document how their perceptions and experiences of a character change over time as they experiment during the preparation process.

The resulting text chronicling the student's observations of the work becomes a case study of his or her growth through the empathic embodiment process of preparing a specific role. Writing throughout music preparation improves students' self awareness and writing skills, builds habits of self-reflection and study into music preparation, and can facilitate discussion with faculty members and stage directors by recording thoughts and ideas to be discussed later. The document also becomes a resource for the student the next time they are engaged to perform the piece. Finally, in documenting the preparation process, the 
singer can track the growth of vocal, musical, and interpretive skills to be utilized throughout his or her career. In this way, the student singer is empowered to consider his or her own development as an artist. The written work therefore documents a two-way process whereby in humanizing the character, the young singer is also humanized.

Recalling David Elliott's work, the role journal exercise cultivates at least three levels of knowledge for the singer: knowledge of the opera and the character in terms of plot details like background information, relationships, and behaviors; knowledge of the embodiment process, for example, what movements evoke what emotions (and vice versa), how the character changes as the singer experiments with new physical ideas resulting from empathic engagement, and how it feels to react to other characters through this character on stage; and self-knowledge as the singer considers how he or she feels throughout the process, what works and what does not, what boundaries are working, what boundaries can be relaxed, and where the singer should cultivate a new boundary if something becomes too intense or too intimate. Finally, singers studying their own role journals may note whether or not they feel their capacity for empathy increased in situations outside of music preparation processes. There is great potential for musical, vocal, interpretative, and personal growth through role preparation that actively exploits the notion of empathy. The writing exercise creates a valuable record of the entire experience while supporting habits of reflection the student can use in preparing other roles.

\section{CONCLUSION}

The implications of developing a theory of empathy for music performance not only are vast but also illuminate the necessity of future research, conceptual as well as practical, in this area. Eerola and Vuoskoski assert, "The research on music and emotion has the capacity of being an area in which progress can be made towards understanding one of the most fascinating aspects of human life which is the cause of so much else beyond music-the full spectrum of emotional experiences" (Eerola \& Vuoskoski, 2013, p. 326). Singers, and actors more generally, have the unique opportunity to explore the emotional experiences of others and of themselves in nearly simultaneous and extremely intimate ways.

Audiences engaging in music performance experiences can empathize with characters even as they may empathize with the performer, reveling in extreme virtuosity or, more subtly, feeling carried away by a beautiful tone or well-crafted phrase. Either way, the capacity for empathic response to yield greater understanding between and among performers and between performers and their audiences is tangible and significant. Hatten and Robinson posit, “...we may well experience emotions triggered as a reaction to those expressed by the music, or experienced by a virtual persona. These emotions may be empathetic (feeling with) or sympathetic (feeling for), and they may be imagined as often as they are actually felt. But however we experience emotions when listening to music, they have the potential to enhance our musical understanding" (Hatten and Robinson, 2012, p. 104). This is the case whether the participant is sitting in the audience or performing on the stage. Musical understanding is only one aspect of the potential for human growth that can be achieved through music performance experiences.

New theories of empathy in music are beginning to dissect the complex web of communication that occurs in live music performance. In related work, researchers explore the implications for empathic development beyond role-playing exercises (Goldstein \& Winner, 2012; Poorman, 2002). According to Goldstein and Winner, "Role-playing beyond early childhood may be a route by which humans come to develop enhanced empathy and gain greater insight into others' beliefs and emotions." (Goldstein \& Winner, 2012, p. 33) Collective role journal study could be used to determine if active cultivation of empathy in music preparation processes has implications for empathic development beyond the musical work.

Empathy, and more specifically, empathic embodiment, is a way to describe the connection between the emotional aspects of vocal performance and the physical (and technical) work of this endeavor. The role journal exercise in score preparation for young singers is one way new concepts in theoretical discourse around empathy in music can find practical application for working artists. Music psychology and performance philosophy find common ground in practical application and there is no better place to start actively utilizing notions of empathy in music than in the next generation of artist practitioners and scholars. 


\section{NOTES}

[1] It is my opinion that processes of embodiment in the preparation and performance of art song are the same as that of opera, and that young singers, if anything, need better tools to prepare art song than opera. This is because frequently in song literature the singer is tasked with embodying a character about whom they are given relatively little information. Although this article focuses on issues of opera role preparation and performance, I believe that the concepts herein apply equally to art song and that the "role journal" exercise is a useful addition to the preparation processes of this repertoire as well. Finally, it is worth mentioning that occasionally singers must deal with issues of character development and empathy in oratorio and chamber music literature, and when appropriate the concepts in this article may also prove useful in these situations.

[2] Another aspect of empathy in the field of vocal performance and analogous to the notion posited by Pembroke is that of the voice teacher and student. Like the patient-physician relationship, the studentteacher relationship requires open communication and clear boundaries to be successful. Details of the empathic student-teacher relationship are outside the scope of this paper; nevertheless, the teacher is likely in the best position to monitor, guide, and evaluate the development of empathy in the student singer. In vocal pedagogy, the teacher must remain aware of the student's abilities and growing potential in terms of vocal, musical, and personal development; the latter only insofar as it affects and influences vocal progress and interpretive ability. Voice teachers must be careful in all cases not to overstep important boundaries into other aspects of the student's life, while respecting that the student is a whole person outside of work in the studio.

\section{REFERENCES}

Blau, H. (1990). Universals of performance; or amortizing play. In R. Schechner \& W. Appel (Eds.), By means of performance: Intercultural studies of theatre and ritual (pp. 250-272). Cambridge: Cambridge University Press.

Brown, B. (2012). Daring greatly: How the courage to be vulnerable transforms the way we live, love, parent, and lead. New York: Penguin Group (USA) Inc.

Eerola, T. \& Vuoskoski, J. K. (2013). A review of music and emotion studies: Approaches, emotion models, and stimuli. Music Perception: An Interdisciplinary Journal, 30(3), 307-340.

Elliott, D. (1991). Music as knowledge. Journal of Aesthetic Education, 25(3), 21-40.

Goldstein, T. \& Winner, E. (2012) Enhancing empathy and theory of mind. Journal of Cognition and Development, 13(1), 19-37.

Gunkle, G. (1963). Empathy: Implications for theatre research. Educational Theatre Journal, 15(1), 15-23.

Hatten, R. \& Robinson, J. (2012). Emotions in music. Music Theory Spectrum, 34(2), 71-106.

Pembroke, N. (2007). Empathy, emotion, and ekstasis in the patient: physician relationship. Journal of Religion and Health, 46(2), 287-298.

Poorman, P. (2002). Biography and role playing: Fostering empathy in abnormal psychology. Teaching of Psychology, 29(32), 32-36.

Putnam, D. (1994). Music and empathy. Journal of Aesthetic Education, 28(2), 98-102.

Schechner, R. (1990). Magnitudes of performance. In R. Schechner \& W. Appel (Eds.), By means of performance: Intercultural studies of theatre and ritual (pp. 19-49). Cambridge: Cambridge University Press. 